\title{
Self Efficacy and Collective Efficacy Beliefs in Relation to Position, Quality of Teaching and Years of Experience
}

\author{
Evelina Dimopoulou \\ Brunel University, London, UK
}

\begin{abstract}
Special Educations teachers' self efficacy and collective efficacy beliefs have been significantly under explored. In order to examine the relationship between those two constructs, the impact on achievement as well as the ways they correlate with demographic factors teachers from an outstanding inner city special school were asked to complete a survey consisting of three questionnaires. This study aimed to look into self efficacy and collective efficacy beliefs of teachers in satisfactory and outstanding schools for children with autism as well as to look at these constructs in relation to position, years of experience, frequency of supervision and other demographic factor. The results suggested the teachers in outstanding schools scored higher for both self efficacy and collective efficacy. Analysis of Variance within groups revealed statistically significant relationships between SE, CE and position and $S E$ and years of experience.
\end{abstract}

\section{Introduction}

Self efficacy and collective efficacy have been the subject of research for the last three decades since Bandura published his work on Social cognitive theory. The theory posits that an individual's behaviour is primarily learned through his or her observation of others as well as through interaction with his or her environment. It provides a framework for understanding, predicting, and changing human behaviour. Thus it is instructive to examine reciprocal relationships between school context (environment) and teacher efficacy beliefs (personal factors) [1].

\section{Research Rationale}

\subsection{Social Cognitive Theory}

The basic principles of Social Cognitive Theory are that: i) Learning can occur by observing the behaviours of others as well as the outcomes of those behaviours ii) Learning can occur without change in behaviour ii) The consequences on behaviour affect learning ii) Cognition affects learning

As individuals, classroom teachers proactively lead their lives and base their actions in relation to these three dimensions of social cognitive theory. The term reciprocal indicates that action is given and received by each subject whilst determinism indicates the production of effects. Because of the varied nature of the interacting influences within this triad relationship, different conditions can produce or lead to different effects. The elements/sources 'behaviour' and 'environment' can extend to include various aspects of the schools' environment. Teachers are being influenced by their students' behaviour, by the way their colleagues or senior managers conduct themselves, by the attitudes of parents and other professionals and individuals involved in every day school life.

\subsection{Teachers' Efficacy and Collective Efficacy}

Both teacher efficacy and collective efficacy have their roots in Albert Bandura's social cognitive theory, which posits that humans have control over their lives through agentive actions [2], [3]. Goddard, Hoy, and Hoy [4] suggest: "Social cognitive theory is employed to explain that the choices teachers make, the ways in which they exercise personal agency, are strongly influenced by collective efficacy beliefs." Thus, an important but overlooked question (which) concerns the nested association between these two influential types of beliefs" [5] in the field of education. Additionally results from Goddard and Goddard [26] treating collective efficacy and teacher efficacy separate constructs but positively and strongly related.

Bandura [6] raised the disputable duality inappropriately equates self-efficacy with selfcentered individualism feeding selfishness, and then pits it against communal attachments and civic responsibility. A sense of efficacy does not necessarily exalt the self or spawn an individualistic lifestyle, identity, or morality that slights collective welfare.

\subsection{Self - Efficacy}

Central to the exercise of control is sense of selfefficacy or "beliefs in one's capabilities to organize and execute a course of action required to produce a given attainment" [3]. Self efficacy theory is based on the principal assumption that psychological procedures, whatever their form, serve as a means of creating and strengthening expectations of personal efficacy [3]. Self-efficacy theory maintains that all processes of psychological change operate through the alteration of the individual's sense of personal mastery or efficacy [3].

Self-efficacy is the idea that people decide how to behave based more on their belief in their own 
capabilities of accomplishment rather than in their knowledge or skills [7]. Bandura [8] clarified that self-efficacy is concerned not with the skills one has but with the capacity of what one can do with whatever skills one possesses. Bandura [3] proposed that efficacy beliefs were powerful predictors of behavior because they were ultimately self-referent in nature and directed toward specific tasks. The predictive power of efficacy has generally been borne out in research, especially when efficacy beliefs are measured concerning specific tasks [9]. Individuals who have the proclivity that they will be successful on a given task are more likely to be so because they take on challenging goals, work hard to achieve them, persevere despite setbacks and manage emotional states [10].Still, self-efficacy helps determine our life choices, it motivates us, and it helps us deal with failures and setbacks in life [11]. Self-efficacy has to do with self-perception of competence rather than actual level of competence. This is an important distinction, because people regularly overestimate or underestimate their actual abilities, and these estimations may have consequences for the courses of action they choose to pursue or the effort they exert in those pursuits [12]. Self efficacy theory acknowledges the diversity of human capabilities and it therefore treats the efficacy system not as an omnibus trait but as a differentiated set of self-beliefs linked to distinct realms of functioning [3].

Efficacy expectation is the individual's conviction that he or she can orchestrate the necessary actions to perform a given task, while outcome expectancy is the individual's estimate of the likely consequences of performing that task at the expected level of competence [8]. The efficacy expectation refers to the individual's ability to organise and execute the actions necessary to accomplish a specific task at a desired level. However, the outcome expectation is concerned with the consequence of the performance. Efficacy expectations determine how much effort people will expend, and how long they will persist in the face of obstacles and adverse experiences [2].In this conceptual system, expectations of personal mastery affect both initiation and persistence of coping behaviour [2].

The preceding analysis of how perceived selfefficacy influences performance is not meant to imply that expectation is the sole determinant of behavior. Expectation alone will not produce desired performance if the component capabilities are lacking [2]. Efficacy expectations differ in magnitude, generality and strength. This means that individuals develop different efficacy expectations based on the difficulty of tasks they are faced with, the spectrum they feel capable of applying their skills as well as the strength of their expectations in mastering the tasks. Discrepancies between expectations and performance are most likely to arise under conditions in which situational and task factors are ambiguous. When performance requirements are ill-defined, people who underestimate the situational demands will display positive discrepancies between self-efficacy and performance attainments [2].Another important distinction is between perceived self efficacy and self esteem. The first is concerned with judgements of personal capability, whereas the second is concerned with judgement of self worth [3]. Also, self esteem reflects a person's overall evaluation or appraisal of his or her own worth however self efficacy is task specific. One may feel highly efficacious to perform an action but they may have a low belief in their capabilities to do something else. According to Pajares 2001 [9], there exists a mis measurement of self-efficacy when efficacy beliefs are not tailored to critical tasks. The judgment of self-efficacy is task and domain specific; therefore, globally defined self-efficacy assessments weaken the effects of self-efficacy [3].Bandura pointed out the necessity of specific assessment for self-efficacy construct and its correspondence with the designated task in order to increase the prediction of academic outcomes.

The rapid pace of informational, social, and technological change is placing a premium on personal efficacy for self-development and selfrenewal throughout the life course [6]. Good selfregulators expand their knowledge and cognitive competencies; poor self-regulators fall behind [8]. Self-regulation is also becoming a key factor in occupational life.

Efficacious people are quick to take advantage of opportunity structures and figure out ways to circumvent institutional constraints or change them by collective action [3].

According to social cognitive theorists people's feelings of self efficacy affect several aspects of their behaviour, including their choice of activities, their goals, their effort and persistence, and ultimately the quality of their performance and their learning. Perceived self-efficacy influences the level of goal challenge people set for themselves, the amount of effort they mobilize, and their persistence in the face of difficulties. Perceived self-efficacy is theorized to influence performance accomplishments both directly and indirectly [13]. Self Efficacy Affects i) Choice of activities Individuals tend to select tasks and activities in which they feel competent and confident and avoid those in which they do not [7].ii)Goals Perceived self-efficacy influences the level of goal challenge people set for themselves [13]. Self-regulated learners direct their learning processes and attainments by setting challenging goals for themselves [14]. Self-regulated learners exhibit a high sense of efficacy in their capabilities, which influences the knowledge and skill goals they set for themselves and their commitment to fulfill these challenges [13]. According to social cognitive 
theory Bandura, goals increase people's cognitive and affective reactions to performance outcomes because goals specify the requirements for personal success iii)Effort and persistence Perceived selfefficacy influences the amount of effort they mobilize [13].The higher the sense of efficacy, the greater the effort, persistence, and resilience. People with a strong sense of personal competence approach difficult tasks as challenges to be mastered rather than as threats to be avoided [7]. iv)Quality of individual performance. Perceived self-efficacy is theorized to influence performance accomplishments both directly and indirectly [13]. High self-efficacy helps create feelings of serenity in approaching difficult tasks and activities. Conversely, people with low self-efficacy may believe that things are tougher than they really are, a belief that fosters anxiety, stress, depression, and a narrow vision of how best to solve a problem. As a consequence, self-efficacy beliefs can powerfully influence the level of accomplishment that one ultimately achieves [7].

\subsection{Teachers' Efficacy}

The task of creating learning environments conducive to development of cognitive skills rests heavily on the talents and self-efficacy of teachers. Those who are well-versed in their subject matter and have a high sense of efficacy about their teaching capabilities can motivate low achievers and enhance their cognitive development [13],[15]. The staffs of successful schools, whether they serve predominantly advantaged or disadvantaged students, have a strong group sense of efficacy to fulfill their academic purpose and resiliency of perceived efficacy in the face of social realities strewn with frustrations [16].

Coladarci and Breton [17] examined the relationship between supervisory visits to the classrooms of teachers assigned to resource room positions. They found that the perceived usefulness of supervisory visits and not the number of visits each year had greater predictive value for teacher efficacy. They also determined that women and older teachers (even those with less experience in the resource room setting) reported higher levels of efficacy than men and younger teachers.

Teachers' efficacy has proven to be an important variable in teacher effectiveness. Research also provides evidence that it is also linked to student attainment. Low teacher efficacy leads to low student efficacy and low academic achievement, which in turn leads to further declines in teacher efficacy [3]. It has been defined as "teachers' belief or conviction that they can influence how well students learn, even those who may be considered difficult or unmotivated" [18p. 628]. The more committed a teacher was to the underlying philosophy of a teaching orientation, the greater the sense that he or she was having an effect on students. This indicates that the more one understands and adheres to a theoretical orientation, the more effective one feels as a teacher [19].

Teachers' self-efficacy beliefs (high internal locus of control and positive attitude to-ward overcoming difficult situations) have been linked to their classroom behaviour [14]. Some teachers feel more efficacious and hold more positive attitudes toward teaching than others [20]. Teachers who believe strongly in their efficacy tend to be open new ideas, more willing to try new methods, more committed to teaching, more resilient to difficulties in work conditions, and tend to be less critical of students who make errors [14], [17], [15], [12].

Viel-Ruma et al. [21] surveyed 104 special educators and found that teacher self-efficacy had a direct effect on job satisfaction. It was further found that collective efficacy directly affected teacher self efficacy but that it did not have a direct effect on job satisfaction. No significant differences were found in reported levels of these areas across subgroups of teachers categorized by teaching level (elementary, middle, and high), teaching setting (self-contained, resource, or inclusion), and certification type (highly qualified, not highly qualified, or emergency).

Teachers' efficacy describes how much a teacher believes he or she can effectively complete the tasks that teaching requires, so that children acquire the skills required for learning. Teaching efficacy, the equivalent to Bandura's outcome expectation, is the teachers' belief that students can be taught despite external factors, such as their family environment [15]. Teachers efficacy beliefs have been studied to an extent within mainstream education and in relation to academic subjects. However less focus has been placed on examining self efficacy within special education.

It is well established that teachers' expectations about students with learning disabilities will affect their instructional goals and methods. Self-efficacy beliefs would be teachers' evaluation of their abilities to bring about positive student change [15] and have been linked to student achievement. Self efficacy and its impact on student achievement have a reciprocal relationship, as also supported by the social cognitive theory and thus affecting each other. Low teacher efficacy leads to low student efficacy and low academic achievement, which in turn leads to further declines in teacher efficacy [3]. However, Ying et al. [22] examined Self-efficacy of early childhood special education teachers and found that lower levels of teachers' self-efficacy were associated with greater gains in children's language and literacy when children with LI were in classroom with a higher instructional support. Coladarci and Breton [17]found that special education resource room teachers with high efficacy scores were satisfied with their position and felt their instructional supervision 
was useful. Those who had low efficacy scores, however, felt the opposite

Along with the construct of teachers' efficacy, collective efficacy beliefs developed in order to explore a group's perceptions of their capabilities to complete the tasks that teaching requires, so that children acquire the skills required for learning.

Student achievement is not only linked to self efficacy but Bandura [3] argued that one powerful construct that varies greatly among schools that is systematically associated with student achievement is the collective efficacy of teachers within a school. Goddard, Hoy, and Woolfolk-Hoy [4] did find a significant relationship between student achievement and collective efficacy beliefs. Also, Goddard and Goddard [23] assumed that when teachers as a group in a school believe that the staff as a whole can be successful, they will be more likely to persist in their own personal efforts to achieve such success. From an organisational perspective, collective teacher efficacy may help to explain the differential effect that schools have on student achievement. Collective teacher efficacy, therefore, has the potential to contribute to our understanding of how schools differ in the attainment of their most important objective the education of [4].

Studies Ashton et al. [14] and more contemporary work has suggested that school organization (principal influence, colleague support, resource support, academic emphasis) help teacher accomplish their goals and may also help improve teacher efficacy. Because self efficacy beliefs influences the selections of activities and environments, teachers are not supported by the school organization may feel low self efficacious and leave their profession.

Efficacious teachers devise and modify instructional strategies to meet students' needs. They spend more time monitoring and facilitating seatwork, and providing whole group instruction [15]. They are more willing to learn and try out new approaches and strategies to meet students' needs [18], [24]. They continually look for ways to help students overcome learning problems. Teachers who succeed in reaching low achieving students combine a strong sense of efficacy with high and realistic expectations for student achievement. They help students to set attainable goals [25]. They not only communicate expectations that their students will achieve but ensure that students are taught the necessary skills and learning strategies [22].

A small number of self-efficacy studies related to teachers of students with disabilities have emerged in recent years. Paneque and Barbetta [26] surveyed 202 special education teachers and the results revealed that overall, the special education teacher efficacy scores in this study were high. The same outcome is supported by the study of Carlson et al. [24] who employed teachers for students with special needs. In regards to the section on self-efficacy, they found that overall special education teachers reported high efficacy A study investigating the sources of self-efficacy among teachers of students with autism; revealed Significant associations between physiological/affective states and self-efficacy, but no associations were observed for the other sources. Allinder [27] found that special education teachers who reported higher levels of self-efficacy were more likely to be organized and likely to engage in instructional planning.

Most studies involving efficacy and special education teachers have focused on attrition and burnout. The results of a recent study by Viel-Ruma et. al [21] indicated that teacher self-efficacy had a direct effect on job satisfaction. It was further found that collective efficacy directly affected teacher self efficacy but that it did not have a direct effect on job satisfaction. No significant differences were found in reported levels of these areas across subgroups of teachers categorized by teaching level (elementary, middle, and high), teaching setting (self-contained, resource, or inclusion), and certification type (highly qualified, not highly qualified, or emergency).

Jennett et al. [19] found that the relationship between a commitment to one's teaching approach and certain dimensions of teaching efficacy and burnout was found to be significant. Implications include the need for adequate training of teachers of students with autism. Although all teachers experience stress, additional stressors exist for special education teachers [19]. Although all special education teachers are potentially at risk for burnout because of the challenging nature of their students, teachers of students with autism may be especially at risk [19]. This is one of the very few studies on teachers for children with Autism. The groups included who work with students with autism in one of two widely used treatment approaches for autism: Applied Behavior Analysis (ABA) and TEACCH (Treatment and Education of Autistic and Related Communication Handicapped Children). The results revealed that for both groups, the commitment score was significantly correlated with the Personal Efficacy dimension of teaching efficacy such that the higher the commitment score the higher the sense of personal efficacy. Also, for both groups, the commitment score was significantly correlated with the Personal Efficacy dimension of teaching efficacy such that the higher the commitment score the higher the sense of personal efficacy. The groups differed neither on their level of personal efficacy nor on their level of general efficacy.

Yeo et. al [28] studied Singapore teachers for low achieving student and found significant differences between novice teachers and experienced teachers emerged in teacher efficacy beliefs in relation to instructional strategies, classroom management, and student engagement. Higher efficacy was reported as 
they matured in their years of professional experience. Highly experienced teachers who had more than fifteen years' teaching experience had a stronger sense of efficacy in providing instructional strategies and engaging students compared to novice teachers who had less than five years' teaching experience. No significant differences at were found for all three dimensions of teacher efficacy against the independent variables of gender and number of levels taught. However, analysis indicated significant differences in teacher efficacy in relation to years of professional experience for instructional strategies; classroom management, and student engagement. Significant differences in teacher efficacy were found in only the dimension of classroom management in relation to teachers' age.

\subsection{Collective Efficacy}

Collective efficacy refers to the perceived "performance capability of a social system as a whole" [3]. Based on social cognitive theory, Bandura [29],[11],[3] expanded the construct of selfefficacy to the larger, social construct of collective efficacy within group settings. Schools are large group settings and teaching cannot occur in isolation. Beliefs of collective efficacy serve functions similar to those of personal efficacy beliefs and operate through similar processes [3].

Personal agency operates within a broad network of socio structural influences" ([3]p. 6) and thus the theory "extends the analysis of mechanisms of human agency to the exercise of collective agency" [3 p.7].Collective efficacy refers to people's shared beliefs that they can work together to produce effects [4].The concept of collective efficacy is similar to self-efficacy in that it focuses on the amount of effort and persistence dedicated to a task and the perception of the success of that task [3].Collective efficacy is likely related to self-efficacy since the perceived sense of group efficacy is related to the individual perceived efficacy of the members of the group [3].

Because the collective performance of a social system involves transactional dynamics, perceived collective efficacy is an emergent group-level property, not simply the sum of the efficacy beliefs of individual members [6]. The stronger the perceived collective efficacy, the higher the groups' aspirations and motivational investment in their undertakings, the stronger their staying power in the face of impediments and setbacks, the higher their morale and resilience to stressors, and the greater their performance accomplishments [6].

People's shared belief in their collective power to produce desired results is a key ingredient of collective agency. Group attainments are the product not only of the shared intentions, knowledge, and skills of its members, but also of the interactive, coordinated, and synergistic dynamics of their transactions [6].Collective agentic adaptability applies at the organizational level as well as the workforce level. Organizations have to be fast learners and continuously innovative to survive and prosper under rapidly changing technologies and global marketplaces [6].

\subsection{Teachers' Collective Efficacy}

While teachers' self-efficacy has been studied in some depth, the concept of collective efficacy has received lower attention [30]. The concept of collective efficacy has been examined less frequently in relatively few studies [30]. Collective teacher efficacy refers to teachers' belief about the collective capability of a group of teachers to influence student achievement [31]. Teacher collective efficacy was measured by teachers' perceptions of school collective efficacy rather than the "schools' sense of collective efficacy as an aggregate of teachers' group-referent efficacy perceptions" [4 p.7]. Bandura [14] summed the teachers' beliefs about their school's capacity to promote different levels of academic attainment. He found that teachers' belief in the school's efficacy as a whole was just as predictive of school performance as teachers' beliefs in their own efficacy. Skaalvik and Skaalvik (2007) [32] suggested that one should attempt raise teachers competencies collectively through school development.

Research has shown that teachers' self-efficacy beliefs influence the achievement of those teachers' students; and at the school level, the collective perception of teacher efficacy in the building also influence how well all students in that particular school perform [11], [3]. Teachers work together to accomplish an established goal in educating children. Pajares [29],[30] also drew from social cognitive theory and agreed upon the collective process of education.

Bandura [11] himself demonstrated a positive effect of collective efficacy and student achievement regardless of socioeconomic status, race, or ethnicity of students. Series of research followed examining the relationship between collective efficacy and student achievement [1], [5],[23],[4]. Goddard, Hoy, and Woolfolk-Hoy [1] did find a significant relationship between schools' student achievement and collective efficacy levels. The assumption is that when teachers as a group in school believe that the staff as a whole can be successful, they will be more likely to persist in their own personal efforts to achieve such success [5].

Collective efficacy for special educators has received less research interest compared to self efficacy. Viel- Ruma et al. [21] found that $t$ a significant relationship between job satisfaction and teacher self-efficacy. Furthermore, a significant 
relationship between teacher self-efficacy and collective efficacy was found. However, a significant relationship between collective efficacy and job satisfaction was not detected.

Following a study of the literature we identified three hypotheses to be tested in this study:

Hypothesis 1: There is be a positive correlation between $\mathrm{SE}$ and $\mathrm{CE}$

Hypothesis 2: There is positive correlation between teacher self-efficacy scores and pupil progress

Hypothesis 3: There will be a positive correlation between SE and years of experience

Hypothesis 4: CE scores will be higher for senior leaders

\section{Objectives}

In the UK, the research on teacher efficacy is extremely sparse and very little is known about how teachers for children with special educational needs perceive their ability to teach. Second, to the best of our knowledge, hitherto, the Tschannen-Moran et al.'s [12] concept of teacher efficacy has not been examined in the UK, and it is interesting to ascertain its applicability to a population of UK teachers for children with special educational needs. Though much has been written about teacher efficacy, the literature is comparatively reticent on how teacher efficacy is understood in the context of teaching children with special educational needs. Following a wider study at UK schools for children with autism, the present study seeks to understand the self efficacy of teachers for children with special educational needs in a rated aoutstanding and satisfactory special schools and to explore the major factors that influence teacher efficacy where it relates to students who have special educational needs. Lastly, the area of collective efficacy for teachers for children with a special educational needs in UK special schools has received very limited, if any attention as far as our literature review reveals.

\section{Methods}

\subsection{Participants}

The participants were teachers and members of the leadership team $(n=39)$ (see Table 1) from $n=27$ (see Table 2) in total special schools catering for special needs students including students with autism in the UK. Of the 39 qualified teachers who agreed to participate in the study 12 were teachers, 11 were lead teachers and 16 were members of the senior management team.
Table 1. List of participants

\begin{tabular}{|c|c|}
\hline Position & N \\
\hline Head & 7 \\
\hline Deputy head & 3 \\
\hline Assistant head & 6 \\
\hline Total Senior & $\mathbf{1 6}$ \\
\hline Lead teacher & 11 \\
\hline Teacher & 12 \\
\hline
\end{tabular}

Table 2. List of schools participating in the questionnaire

\begin{tabular}{|c|c|c|c|c|}
\hline $\begin{array}{l}\text { ASD } \\
\text { provision }\end{array}$ & & Type & & $\begin{array}{l}\text { Quality of } \\
\text { Teaching }\end{array}$ \\
\hline ASD & 11 & Primary & 6 & Outstanding 19 \\
\hline $\begin{array}{l}\text { SEN } \\
\text { Mainstream } \\
\text { (ASD Unit) }\end{array}$ & $\begin{array}{r}6 \\
10 \\
\end{array}$ & $\begin{array}{l}\text { Secondary } \\
\text { Primary \& } \\
\text { Secondary }\end{array}$ & 12 & Satisfactory 9 \\
\hline Total & 27 & & & \\
\hline
\end{tabular}

All schools were contacted via email for their consent to participate in the study. Participants received paper copies of the questionnaires which they return to the researcher in a self addressed envelope which had been provided.

\subsection{Measures}

Two questionnaires were be used to measure self efficacy, collective efficacy and one questionnaire was used to collect demographic data. To measure self efficacy a 30 item, 9 points Likert Scale was used adapted from Dawson, 2010 Teacher Self Efficacy Scale Disabilities TSESD (alpha=.973) To measure Collective Efficacy, a 12 item, 9 points Likert Scale queastionnaire was used adapted from Tschannen-Moran, Barr, 2004 Collective Teachers Beliefs (alpha $=.950)$. Also, a third demographic fifteen questions regarding, age, position at school, years of experience in various settings, training, qualifications, interventions used was also included. The questionnaires were distributed in the form of hard copies school and brief description of the aims of the study will be provided as well as a statement about the anonymity and the protection of personal data of the participants.

\section{Results}

A total number of 39 questionnaires were received from participants from 27 special schools catering for pupils with autism. Of those 19 were judged by Ofsted as Outstanding in terms of their quality of teaching and 9 as Satisfactory

Analysis of Variance(ANOVA) was carried out in order to identifying within groups significance for 
CE and SE for identified demographic independent variables (position, age, years of teaching experience, years of teaching in ASD school, frequency of supervision, Teaching Interventions). Pearson's Test of Linear Correlation was used to establish correlation between Self Efficacy and Self Efficacy.

Hypothesis 1: There is be a positive correlation between SE and CE

A Pearson's Test of Linear Correlation Pr $=0.512$ showed an overall positive correlation between self efficacy and collective efficacy.

Hypothesis 2: There is positive relationship between teacher self-efficacy scores and quality of teaching Analysis of Variance revealed that there is statistically significant difference in self efficacy between schools with outstanding and satisfactory pupil progress $(\mathrm{p}=0.004)$ (see Table 3$)$.

Table 3. Difference in self efficacy between schools with outstanding and satisfactory pupil progress

\begin{tabular}{|l|l|l||l|}
\hline \multicolumn{1}{|c|}{ Group } & N & Mean & $\begin{array}{c}\text { Standard } \\
\text { Deviation }\end{array}$ \\
\hline OUTSTANDING & 31 & 8.18 & 0.575 \\
\hline SATISFACTORY & 8 & 7.033 & 1.825 \\
\hline
\end{tabular}

Hypothesis 3: There will be a positive relationship between SE and years of experience

The result of Analysis of variance showed that there is statistically significant difference in SE amongst staff with different years of teaching experience $(\mathrm{p}=$ 0.01) (see Table 5, Graph 1) with those with more years with experience exhibiting higher levels of SE. This applies to years of experience teaching students with autism.

Table 5. The result of analysis of variance

\begin{tabular}{|l||l|l|l|}
\hline \multicolumn{1}{|c|}{ Group } & $\mathbf{N}$ & Mean & \multicolumn{1}{|c|}{ Standard Deviation $^{\mathbf{3}}$} \\
\hline 11 TO 15 & 10 & 8.243 & 0.516 \\
\hline 16 OR MORE & 7 & 8.695 & 0.26 \\
\hline 3 OR LESS & 2 & 7.778 & 0.691 \\
\hline 4 TO 6 & 4 & 7.878 & 0.635 \\
\hline 7 TO 10 & 8 & 7.902 & 0.564 \\
\hline
\end{tabular}

Graph 1. Self Efficacy Mean

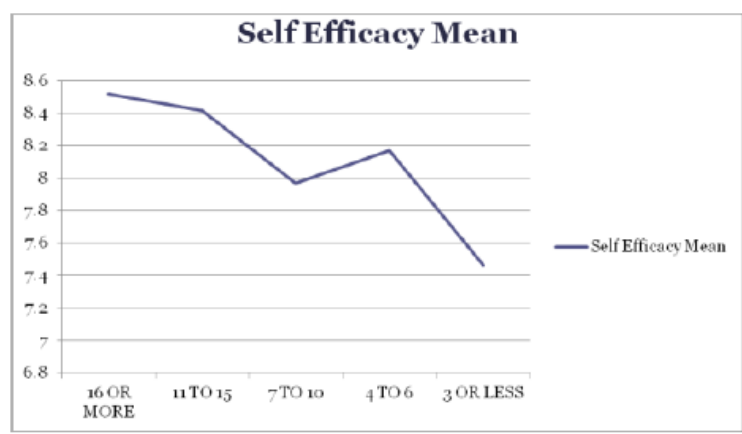

However, analysis of Variance did not indicate statistically significant differences in SE when overall years of teaching experience was analysed in relation to self efficacy (see Table 6).

Table 6. Analysis of variance overall years of teaching experience was analysed

\begin{tabular}{|l|l|l|l|}
\hline \multicolumn{1}{|c|}{ Group } & $\mathbf{N}$ & Mean & \multicolumn{1}{c|}{ Standard Deviation $^{\mathbf{3}}$} \\
\hline 11 TO 15 & 4 & 8.362 & 0.643 \\
\hline 16 OR MORE & 14 & 8.362 & 0.495 \\
\hline 3 OR LESS & 2 & 7.344 & 0.079 \\
\hline 4 TO 6 & 3 & 7.837 & 0.783 \\
\hline 7 TO 10 & 8 & 8.108 & 0.517 \\
\hline
\end{tabular}

Hypothesis 4: CE scores will be higher for senior leaders (SLT)

The mean scores of collective efficacy for members of the leadership team was collectively higher compared to non SLT members. (see Table 7, Graph 2) SE and CE were both lower for deputy heads compared to heads and assistant heads. The difference in SE between SLT and non SLT members were less compared to $\mathrm{CE}$.

Table 7. The mean scores of collective efficacy for members of the leadership team

\begin{tabular}{|l|l|l|l|}
\hline Group & & & Standard \\
\cline { 4 - 4 } & $\mathbf{N}$ & Mean & Deviation3 \\
\hline SLT & 16 & 8.385 & 0.767 \\
\hline NON SLT & 23 & 7.511 & 1.107 \\
\hline
\end{tabular}


Graph 2. Comparison of collective efficacy mean and self efficacy mean

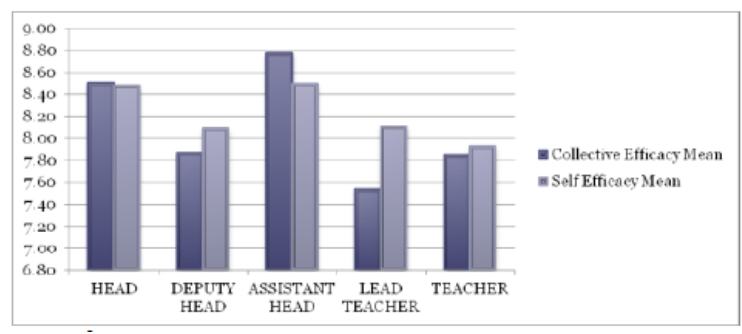

Analysis of Variance for the rest of the independent parameters (age, frequency, of supervision and interventions used) did not reveal any statistically significant results for $\mathrm{SE}$ and $\mathrm{CE}$ amongst participants within each of the groups of the independent variables.

\section{Discussion}

Self efficacy and collective efficacy in special education have not been sufficiently explored. Both constructs are linked to student achievement however again there is lack of robust and wide evidence to apply this assumption to special education students. The existing research does suggest that the more efficacious teachers are the better they perform impacting on the quality of teaching. However social cognitive theory supports that Self-efficacy has to do with self-perception of competence rather than actual level of competence.

This study revealed a positive relationship between self efficacy and collective efficacy. There is not sufficient number of studies to support this argument. Goddard and Goddard [23] and Skaalvik and Skaalvik [32]suggested moderate positive relations between perceived collective efficacy and individual teacher self-efficacy.

Our hypothesis suggested a positive relationship between self efficacy and years of experience. There is not enough research to support this argument and there is also seem to be a dichotomy in the small amount of available research. A Klassen and Ming Chiu [33] found that years of experience has nonmonotonic relationships with all teacher selfefficacies; on average, classroom management selfefficacy increases from 0 years of experience to about 23 years of experience and falls afterwards. On the other hand Khurshod et al. [34] who studied 75 secondary school teachers found that experienced teachers have high self-efficacy.

Our fourth hypothesis suggested higher self efficacy and collective efficacy levels for members of the leadership team compared to teachers. There is a body of research on self efficacy and collective efficacy in positions of leadership but not in relation to non leadership staff. Khurshod et al. [34] found that designation affects teacher's self-efficacy; results shows that head teachers have higher selfefficacy than class teachers. Soisson [35] examined outstanding middle school in Oregon and found that principals' collective efficacy beliefs were higher than those of teachers. The lack of evidence from special education and indeed UK makes it difficult to draw conclusions and compare the results of this study.

\section{Conclusion}

Self efficacy and collective efficacy in special education are highly under researched. There certainly is a link between SE, CE and achievement however more research is required to establish solid links between efficacy and school performance.

\section{References}

[1] R. D. Goddard, W. K. Hoy, A. W. Hoy, "Collective efficacy: Its meaning, measure, and impact on student achievement", American Education Research Journal, 2000, 37, pp. 479-507.

[2] A.Bandura, Social learning theory, Englewood Cliffs, NJ: Prentice Hall, 1977.

[3] Bandura, Self-efficacy: The exercise of control. New York: Freeman, 1997.

[5] R. D. Goddard, "Collective efficacy: A neglected construct in the study of school sand student achievement", Journal of Educational Psychology, 2001, 93(3), pp. 467476.

[6] Bandura, "Social cognitive theory: An agentic perspective", Annual Review of Psychology, 2001, 52, pp. $1-26$.

[7] F. Pajares, Overview of social cognitive theory and of self-efficacy. http://www.emory.edu/EDUCATION/ mfp/eff.html, 2002, (Access date: 20 December 2011).

[8] A. Bandura, Social foundations of thought and action: A social cognitive theory, Englewood Cliffs, NJ: Prentice Hall.Association, New York, 1986.

[9] F. Pajares, D. H Schunk, "Self-beliefs and school success: Self-efficacy, self-concept, and school achievement”. In R. Riding \& S. Rayner (Eds.), Selfperception, London: Ablex Publishing, 2001, pp. 239-266

[10] J. A. Ross, P. Gray, “Transformational leadership and teacher commitment to organizational values: The mediating effects of collective teacher efficacy". School Effectiveness and School Improvement, 2006, 17(2), pp. 179-199.

[11] Bandura, "Self-efficacy", In V. S. Ramachaudran (Ed.), Encyclopedia of human behavior , Vol. 4. New York: Academic Press, 1994, pp. 71-81. 
[12] M. Tschannen-Moran, A. W. Hoy, W. K. Hoy, "Teacher efficacy: Its meaning and measure". Review of Educational Research, 1998, 68, pp. 202-248.

[13] J. Zimmerman, A. Bandura, M. Martinez-Pons, "Selfmotivation for academic attainment: The role of selfefficacy beliefs and personal goal setting". American Educational Research Journal, 1992, 29, pp. 663-676.

[14] Bandura, (1989) "Social cognitive theory", in R. Vasta (Ed.), Annals of child development. Vol. 6. Theories of Child Development (1-60). Greenwich, CT: JAI Press.

[15] S. Gibson, M. Dembo." Teacher efficacy: A construct validation", Journal of Educational Psychology, 1984, 76(4), pp. 569-582.

[17] T. Coladarci, W.Breton, "Teacher efficacy, supervision, and the special education resource-room teacher". Journal of Educational Research, 1997, 90, 230-239.

[16] L. Lightfoot,."The Lives of Teachers," in The Handbook of Teachers and Policy [Eds. Lee Shulman and Gary Sykes], New York: Longman, Inc., 1983.

[18] R. Guskey, "Teacher efficacy, self-concept, and Literacy Information and Computer Education Journal (LICEJ), Volume 3, Issue 1, March 2012

Copyright (C) 2012, Infonomics Society 518 attitudes toward the implementation of instructional innovation". Teaching and Teacher Education, 1988, 4, pp. 63-69.

[19] H. K. Jennett, S. L. Harris, G. B. Mesibov, "Commitment to philosophy, teacher efficacy, and burnout among teachers of children with autism". Journal of Autism and Developmental Disorders, 2003, 33, pp. 583593R.

[20] S. E. Rimm-Kaufman, B. E. Sawyer, "Primarygrade teachers' self-efficacy beliefs, attitudes toward teaching, and discipline and teaching practice priorities in relation to the responsive classroom approach". Elementary School Journal, 2004, pp.104-321.

[22] M. K. Alderman, "Motivation for at-risk students", Educational Leadership, 1990, 48, pp.27-30.

[21] K. Viel-Ruma, D. Houchins, K. Jolivette, K. Benson, "Efficacy beliefs of special educators: The relationships among collective efficacy, teacher self effícacy, and job satisfaction". Teacher Education and Special Education, Volume: 33, 2010

[22] G. Ying, J.M. Dynia, C.Y. Pelatti, L.M. Justice "Selfefficacy of early childhood special education teachers: Links to classroom quality and children's learning for children with language impairment", Teaching and Teacher Education, 2014, Vo. 139, p 12-21.

[23] R. D Goddard, Y. L. Goddard, "A multi level analysis of the relationship between teacher and collective efficacy in urban schools". Teacher and Teacher Education, 2001, 17 , pp. 807-818.
[24] E. Carlson, H. Lee, K. Schroll, S. Klein, S. Willing "Final Report of the Study of Personnel Needs in Special Education". Washington, DC: Office of Special Education Programs, U.S. Department of Education, 2002.

[25] J. A. Ross, "The antecedents and consequences of teacher efficacy". In J. Brophy (Ed.), Advances in research on teaching, vol. 7, Greenwich: JAI, 1998, pp. 49-73.

[26] O. M., Paneque, P. M. Barbetta,"A study of teacher efficacy of special education teachers of English language learners with disabilities". Bilingual Research Journal, 2006, 30, pp.171-193.

[27] R.M. Allinder, "The relationship between efficacy and the instructional practices of special education teachers and consultants". Teacher Education and Special Education, 1994, 17, pp.86- 95.

[28] L.S. Yeo, R P. Ang, W.H. Chong, V.S. Huan, C.L. Quek, "Teacher Efficacy In the Context of Teaching Low Achieving Students", Current Psychology; 2008, Vol. 27 Issue 3, p. 192-204.

[29] F. Pajares, "Self-efficacy beliefs in academic settings". Review of Educational Research, 1996, 66(4), pp. 543-578.

[30] F. Pajares, "Current directions in self-efficacy research". In Maehr and P. R. Pintrich (Eds.), Advances in Motivation and Achievement, Greenwich, CT: JAI Press, 1997, pp. $1-49$

[31] D. Goddard, L. LoGerfo, W. K. Hoy, "High school accountability: The role of perceived efficacy". Educational Policy, 2004b, 18, pp. 403-425.

[32] M. Skaalvik, S. Skaalvik, "Dimensions of teacher self-efficacy and relations with strain factors, perceived collective teacher efficacy, and teacher burnout". Journal of Educational Psychology, 2007, 99, pp. 611-625.

[33] R.M Klassen, M.M Chiu, "Effects on Teachers' SelfEfficacy and Job Satisfaction:Teacher Gender, Years of Experience, and Job Stress", Journal of Educational Psychology, 2010, Vol. 102, Issue 3, p741-756.

[34] F. Khurshid, F.N. Qasmi, N. Ashraf, "The relationship between teachers' self efficacy and their perceived performance", Interdisciplinary Journal of Contemporary Research In Business, 2012, Vol. 3. No 10. 